\title{
DYSTHANASIA AND/OR FUTILE CARE IN THE INTENSIVE CARE UNITS OF A SPECIALTY HOSPITAL IN EL BAJío region, in Mexico
}

\author{
EM Olivares-Durán ${ }^{1 *}$, AM Madrigal-Arcos ${ }^{1,2}$ \\ From ESICM LIVES 2015 \\ Berlin, Germany. 3-7 October 2015
}

\section{Introduction}

End-of-life care is emerging as a comprehensive area of expertise in the ICU and demands the same high level of knowledge and competence as all other areas of ICU practice ${ }^{1}$.

\section{Objectives}

To estimate the frequency with which dysthanasia and/ or futile care is practiced in adult and pediatric intensive care units (ICUs) of a specialty hospital in El Bajío Region, in Mexico, and to identify the main factors associated with their occurrence.

\section{Methods}

A survey on the "Factors Involved in Dysthanasia and/or Futile Care", designed by the authors, was applied to medical and nursing staff of every ICUs of the High Specialty Regional Hospital of El Bajío (HRAEB) along a period of 5 months. Staff participation was voluntary and the forms were self-reported. The interviews were conducted individually, in a private setting, and within a context of confidentiality and anonymity.

\section{Results}

30 critical care nurses and 20 physicians (adult intensivists, cardiologists, pediatric intensivists, neonatologists) from the ICUs, of all shifts, participated. $72 \%$ admitted to have practiced, at least once, dysthanasia and/or futile care, without a significant difference between in physicians $(70 \%)$ and nurses $(76.6 \%) .56 \%$ of respondents stated that the frequency with which they incur in any practice deemed by themselves as compatible with dysthanasia

${ }^{1}$ High Specialty Regional Hospital of El Bajío (HRAEB), Adult Intensive Care Unit, León, Mexico

Full list of author information is available at the end of the article and/or futile care is $30 \%$ of their cases. The respondents obtained high or very high grades (from $86 \%$ to 98\%) regarding their knowledge about: what a terminal illness is, what a terminal patient is, what dysthanasia is and what futile care is. $52 \%$ of respondents (physicians and nurses) reported not knowing the patients' rights. The right most mentioned by respondents (24\%) was the right to die with dignity.

\section{Conclusions}

$72 \%$ of the ICUs' staff who was surveyed for this project affirmed to have practiced, at least once, dysthanasia and/ or futile care. This was associated with their serious lack of knowledge about patients' rights (52\%). This report should lead us to a deep reflection on the urgent need for addressing bioethical and humanization matters of the processes of education, training, supervision and practice of Intensive Medicine and Nursing.

\section{Grant Acknowledgment}

This research did not receive any grant from any funding agency of the public, commercial, or not-for-profit sectors.

\section{Authors' details}

'High Specialty Regional Hospital of El Bajío (HRAEB), Adult Intensive Care Unit, León, Mexico. ${ }^{2}$ University of Guanajuato, Department of Nursing and Obstetrics, Campus León, León, Mexico.

Published: 1 October 2015

\section{Reference}

1. Recommendations for end-of-life care in the intensive care unit: A consensus statement by the American College of Critical Care Medicine. Crit Care Med 2008, 36:953-963.

doi:10.1186/2197-425X-3-S1-A655

Cite this article as: Olivares-Durán and Madrigal-Arcos: DYSTHANASIA AND/OR FUTILE CARE IN THE INTENSIVE CARE UNITS OF A SPECIALTY HOSPITAL IN EL BAJío region, in Mexico. Intensive Care Medicine Experimental 2015 3(Suppl 1):A655.

\section{SpringerOpen ${ }^{\odot}$}

C 2015 Olivares-Durán et al.; This is an Open Access article distributed under the terms of the Creative Commons Attribution License (http://creativecommons.org/licenses/by/4.0), which permits unrestricted use, distribution, and reproduction in any medium, provided the original work is properly cited. 